\title{
Hydroxyethyl starch for perioperative goal- directed fluid therapy in 2020: a narrative review
}

\author{
Alexandre Joosten ${ }^{1,2,3^{*}}$ (D), Sean Coeckelenbergh ${ }^{1}$, Brenton Alexander ${ }^{4}$, Amélie Delaporte ${ }^{5}$, Maxime Cannesson ${ }^{6}$, \\ Jacques Duranteau ${ }^{2}$, Bernd Saugel ${ }^{7,8}$, Jean-Louis Vincent ${ }^{9}$ and Philippe Van der Linden ${ }^{10}$
}

\begin{abstract}
Background: Perioperative fluid management - including the type, dose, and timing of administration - directly affects patient outcome after major surgery. The objective of fluid administration is to optimize intravascular fluid status to maintain adequate tissue perfusion. There is continuing controversy around the perioperative use of crystalloid versus colloid fluids. Unfortunately, the importance of fluid volume, which significantly influences the benefit-to-risk ratio of each chosen solution, has often been overlooked in this debate.

Main text: The volume of fluid administered during the perioperative period can influence the incidence and severity of postoperative complications. Regrettably, there is still huge variability in fluid administration practices, both intra-and inter-individual, among clinicians. Goal-directed fluid therapy (GDFT), aimed at optimizing flowrelated variables, has been demonstrated to have some clinical benefit and has been recommended by multiple professional societies. However, this approach has failed to achieve widespread adoption. A closed-loop fluid administration system designed to assist anesthesia providers in consistently applying GDFT strategies has recently been developed and tested. Such an approach may change the crystalloid versus colloid debate. Because colloid solutions have a more profound effect on intravascular volume and longer plasma persistence, their use in this more "controlled" context could be associated with a lower fluid balance, and potentially improved patient outcome. Additionally, most studies that have assessed the impact of a GDFT strategy on the outcome of high-risk surgical patients have used hydroxyethyl starch (HES) solutions in their protocols. Some of these studies have demonstrated beneficial effects, while none of them has reported severe complications.

(Continued on next page)
\end{abstract}

\footnotetext{
* Correspondence: Alexandre.Joosten@erasme.ulb.ac.be; joosten-

alexandre@hotmail.com

${ }^{1}$ Department of Anesthesiology, Erasme Hospital, Université Libre de Bruxelles, Brussels, Belgium

2 Department of Anesthesiology and Intensive Care, Hôpitaux Universitaires

Paris-Sud, Université Paris-Sud, Université Paris-Saclay, Hôpital De Bicêtre, Assistance Publique Hôpitaux de Paris (AP-HP), Le Kremlin-Bicêtre, France Full list of author information is available at the end of the article
}

(c) The Author(s). 2020 Open Access This article is licensed under a Creative Commons Attribution 4.0 International License, which permits use, sharing, adaptation, distribution and reproduction in any medium or format, as long as you give appropriate credit to the original author(s) and the source, provide a link to the Creative Commons licence, and indicate if changes were made. The images or other third party material in this article are included in the article's Creative Commons licence, unless indicated otherwise in a credit line to the material. If material is not included in the article's Creative Commons licence and your intended use is not permitted by statutory regulation or exceeds the permitted use, you will need to obtain permission directly from the copyright holder. To view a copy of this licence, visit http://creativecommons.org/licenses/by/4.0/. The Creative Commons Public Domain Dedication waiver (http://creativecommons.org/publicdomain/zero/1.0/) applies to the data made available in this article, unless otherwise stated in a credit line to the data. 


\begin{abstract}
(Continued from previous page)
Conclusions: The type and volume of fluid used for perioperative management need to be individualized according to the patient's hemodynamic status and clinical condition. The amount of fluid given should be guided by well-defined physiologic targets. Compliance with a predefined hemodynamic protocol may be optimized by using a computerized system. The type of fluid should also be individualized, as should any drug therapy, with careful consideration of timing and dose. It is our perspective that HES solutions remain a valid option for fluid therapy in the perioperative context because of their effects on blood volume and their reasonable benefit/risk profile.
\end{abstract}

Keywords: Colloid, Balanced crystalloids, Fluid responsiveness, Hemodynamic monitoring, Acute renal failure, Outcome

\section{Background}

Perioperative fluid therapy is a routine aspect of daily clinical practice for most anesthesiologists but remains a therapeutic challenge. One of the most complex aspects of perioperative fluid therapy is determining how much fluid to give each patient. Numerous observational studies have reported a strong association between both excessive and insufficient perioperative fluid administration and an increased risk of postoperative complications [1-6]. As it is difficult to predict or anticipate the volume of fluids a patient will need during surgery, several national and international societies recommend using goal-directed fluid therapy (GDFT) based on advanced hemodynamic monitoring in patients undergoing high-risk surgery [7-10]. GDFT has been promoted as helping to standardize fluid administration using recommended and validated protocols, thereby improving patient outcomes and decreasing costs [11-13]. Despite an abundance of literature on this topic, the volume of fluid that should be administered to achieve and maintain normovolemia is still the subject intense controversy.

The choice of intravenous fluid type has also been a subject of passionate debate, recently refueled by the publication of several large, prospective, randomized studies in different patient populations. These studies have demonstrated the impact of intravenous fluid solutions on patient outcomes, particularly in critically ill patients in the intensive care setting [14]. Although their results have created intense controversy, these studies have clearly demonstrated that the need for intravenous infusions may vary considerably in a given patient during the course of his/her clinical course [15]. They have also indicated that results observed in critically ill patients cannot be extrapolated to surgical patients. The R.O.S.E. conceptual model (Resuscitation, Optimization, Stabilization, Evacuation) condenses precisely a dynamic approach of fluid therapy allowing to maximize its benefits while reducing its harms [16]. Importantly, surgical patients receiving i.v fluids in the perioperative setting are typically in the "Optimization phase" and this specific category of patients will be discussed in the present review. Therefore, the goal of this narrative review article is to discuss the fundamentals of perioperative fluid therapy through four frequently asked questions regarding perioperative fluid therapy.

\section{Main text}

Question 1: should we administer fluids in a goal-directed fashion?

YES.

There is quite strong evidence to support the benefits of GDFT in high-risk patients undergoing major surgical procedures $[9,11]$. Indeed, over the past 15 years, several meta-analyses of the impact of GDFT in patients undergoing moderate and high-risk surgeries have observed that GDFT improves outcome compared with routine care $[8,11,17-20]$. However, the studies included in these meta-analyses are highly heterogeneous, with different protocols, different physiologic endpoints, and different technologies to measure stroke volume and cardiac output. Interestingly, these studies demonstrate that patients in the GDFT groups also received highly variable volumes of fluids. While clinical pathways and protocols are not designed to eliminate all forms of variability, differences in individual care should be patient driven and not practitioner dependent. Adequate GDFT for patients undergoing major surgery requires that stroke volume or cardiac output are monitored to assess fluid responsiveness and that an algorithm is designed that will be applied by all members of the anesthesia team. Admittedly, some studies have not demonstrated a beneficial effect of GDFT on patient outcome [21-25]. However, these studies were mainly underpowered and/ or conducted in relatively healthy patients with minimal fluid shift and blood loss [23, 24, 26-28]. Additionally, compliance to the study protocols must be examined closely when evaluating the results [29]. Pearse et al. nicely demonstrated that when a GDFT protocol is consistently applied, the treatment effect is strengthened [25]. Indeed, according to the authors of this study, "In the prespecified adherence-adjusted analysis conducted using established methods, the observed treatment effect was strengthened when the 65 patients whose care was non adherent were assumed to experience the same 
outcome as if they had been allocated to the alternative group (RR, 0.80; 95\% CI, 0.61-0.99; $P=0.04$ )". Another point of interest is that use of a GDFT protocol has never been associated with a deleterious effect for the patient. It is therefore not surprising that GDFT has been included in the national expert recommendations of several countries, including the United Kingdom and France [7, 10]. Obviously, some questions related to GDFT remain unanswered. What is the ideal endpoint? What is the best monitor to use when applying GDFT? What should be the ideal maintenance crystalloid infusion rate? What is the ideal "type" of fluid (crystalloid alone or a combination of crystalloid and colloid)? What is the ideal target patient population? Should GDFT protocols include inotropic support?

Most institutions and anesthesiology departments have written protocols and standardized pathways for management of severe perioperative bleeding, although "level $1 \mathrm{~A}$ " evidence is mostly absent [30,31]. Application of these protocols has demonstrated reduced variability in treatment and improved quality of care [32]. In our opinion, the same approach should be applied to hemodynamic and fluid management. In accordance with international guidelines, institutions should be encouraged to establish a written GDFT protocol. These GDFT strategies can rely on pulse pressure variation alone, enabling use in the absence of a cardiac output monitor and in clinical settings where more advanced monitoring is not available. As a result, implementing GDFT should not be associated with a large increase in costs.

\section{Question 2: is it possible to improve current GDFT?}

YES.

Despite the development of minimally invasive monitoring devices and the simplification of GDFT protocols over the last decade [33, 34], clinicians' compliance with the application of these protocols remains poor, ranging between 62 and 87\%, even in ideal study conditions $[9,35]$. Adherence of less than $50 \%$ to protocols is reported in daily practice across different medical specialties, but at least $80 \%$ adherence is required to observe improved clinical outcomes [36-38]. Effective management and application of GDFT algorithms often requires careful monitoring with frequent and repeated interventions by the clinician [34]. This can be particularly difficult for anesthesiologists who work in a stressful environment and are subject to numerous stimuli and distractions, all of which can decrease their attention and concentration.

In a recent prospective feasibility study, Menger et al. paired a second anesthesiologist, who was specifically dedicated to applying the written GDFT protocol, with the primary anesthesiologist in charge of the patient.
With this "active clinical decision support system", the authors observed a protocol compliance of about $85 \%$ [39]. Unfortunately, such an approach is very costly in terms of human resources, which limits its implementation [40]. Over the past decade, members of our team have developed a closed-loop administration system based on the simultaneous analysis of multiple advanced hemodynamic indices provided by a minimally-invasive hemodynamic monitoring device and controlled by a computer [27, 41-43] (Fig. 1). With this system, the administration of multiple fluid boluses is completely automated, requiring only minimal human intervention. We have demonstrated that implementation of this "computer system" resulted in less intraoperative time spent in a preload-dependent state (stroke volume variation > $13 \%)$ compared to a manually applied protocol, using both minimally invasive and noninvasive technologies $[43,44]$. Implementation of these systems at the patient's bedside has also been associated with better patient outcomes compared to routine care [45]. The software for this technology has now been implemented into the EV1000 monitoring device as a real-time clinical decision support system and is widely available for clinical use [46]. Of note, after the initial development of our closed-loop system for GDFT administration, our attention has now shifted to automated system allowing tight vasopressor infusion in order to be able to design a fully automated system for perioperative goal directed hemodynamic therapy, allowing the co-titration of fluid and vasopressors [47-52].

\section{Question 3: is there a place for a colloid solution in GDFT protocols? \\ YES.}

From a physiological perspective, it seems obvious that colloid solutions have a role in GDFT protocols [53]. Colloid solutions remain longer intravascularly than do crystalloid solutions, continuing to create oncotic pressure, so theoretically they are associated with a decrease in the amount of fluid needed to achieve and maintain hemodynamic goals [54-57]. The exclusive use of crystalloid solutions, because of their lower volume effect and shorter intravascular persistence, is associated with greater volumes of fluid administration resulting in fluid overload and its potential complications in the perioperative period [57]. Indeed, compared to colloid solutions, greater crystalloid fluid volumes may be required to restore intravascular volume [58]. In an experimental study, Hiltebrand et al. showed that compared to a crystalloid solution (Ringer's lactate), administration of HES boluses, guided by the measurement of venous oxygen saturation, reduced the total volume of fluid infused and, more importantly, improved microcirculatory blood flow and intestinal oxygen partial pressure after 


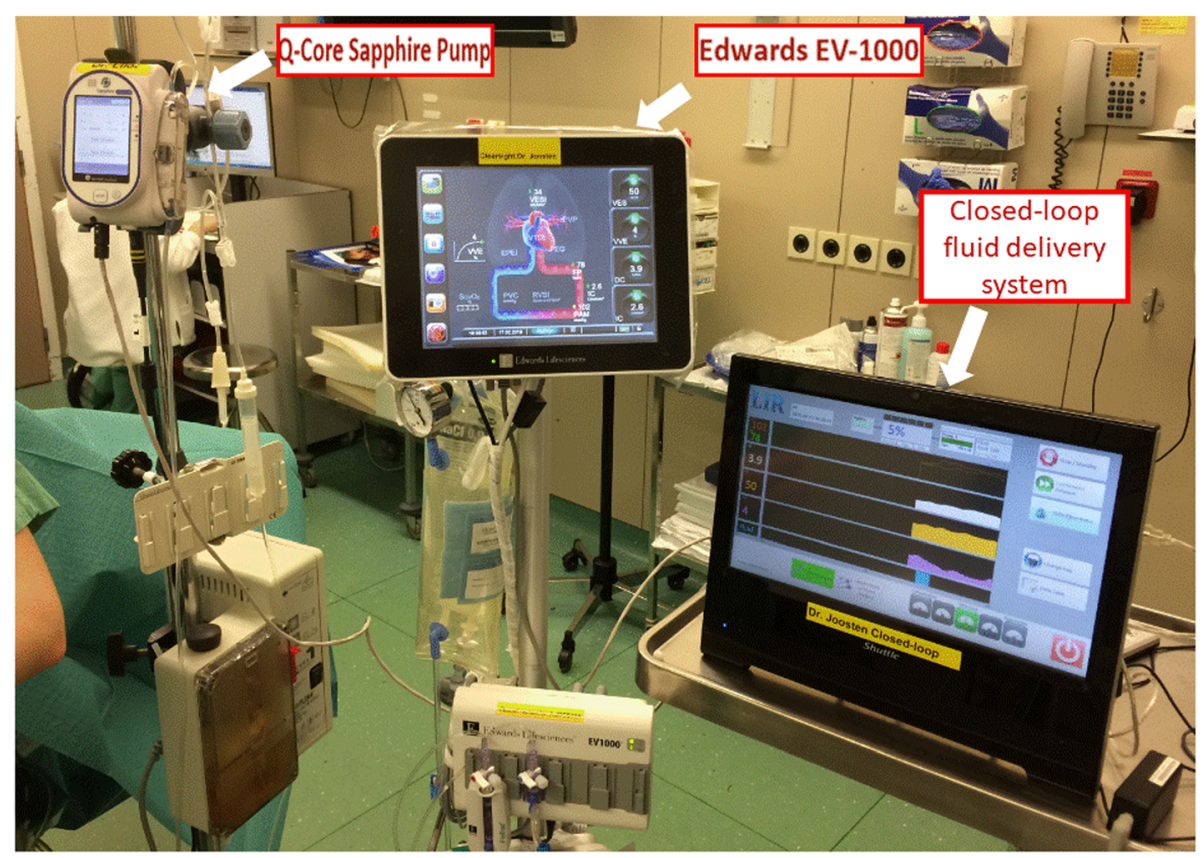

Fig. 1 Closed-loop fluid management set-up. The closed-loop was connected with the EV1000 monitoring device with an analog-to-digital adapter connected to the EV1000 analog output device. The closed-loop software was run on a Shuttle X50 touchscreen PC. A Q-core Sapphire Multi-Therapy Infusion Pump (Q-Core, Netanya, Israel) was used to deliver mini fluid challenges of $100 \mathrm{ml}$ and was linked to the closed-loop through a serial connection

abdominal surgery [59]. Excessive fluid administration (mainly crystalloids) has been shown to increase the risk of intestinal tissue edema, leading not only to delayed resumption of intestinal activity and anastomotic leakage, but also to a risk of pulmonary edema and postoperative respiratory complications, all of which increase the hospital length of stay $[6,60]$. The use of large volumes of isotonic saline $(0.9 \% \mathrm{NaCl})$ also leads to an increased risk of hyperchloremic acidosis, which can lead to gastrointestinal and renal dysfunction, secondary to the vasoconstrictive properties of the chloride ion [61]. Importantly, volume effects of colloids have been demonstrated to be context sensitive [62]. Administration of iso-oncotic colloids (5\% albumin or 6\% hydroxyethyl starch) during acute bleeding when carefully maintaining intravascular normovolemia led to volume effects of more than $90 \%[63,64]$. In contrast, preoperative volume loading in a non-bleeding patient resulted in a volume effect of only $30-35 \%$, two-third of the given bolus leaving the vascular space toward the interstitial compartment within minutes [65]. Colloids and crystalloids cannot be exchanged by simply adapting the amount [66]. Recently, Orbegozo Cortes et al. reviewed all studies comparing crystalloid and colloid solutions in all types of patients (medical, surgical, and trauma patients), many of which likely had altered vascular permeability [54]. They reported that greater volumes were required to achieve similar targets with crystalloid than with colloid solutions (estimated ratio: 1.50; 95\% CI: 1.361.65). Figure 2 represents the comparison of the crystalloids vs colloids ratio extracted from the study from Orbegozo et al. in the context of an administration of crystalloids without or with a certain amount of colloids [54]. These results were confirmed by Annane et al. in the CRISTAL study [67]. Although this ratio would be expected to be greater than 1.5 , it is important to note that none of these studies strictly compared a pure colloid with a pure crystalloid strategy as the colloid groups also always received some crystalloid infusion.

In the context of perioperative GDFT, there are very few clinical data evaluating the influence of the type of intravenous fluid used on outcome. Not surprisingly, there are currently no recommendations as to the type of fluid (crystalloids or colloids) that should be used to optimize a patient's intravascular blood volume in the perioperative setting. It is interesting to note that $85 \%$ of the GDFT studies published in the literature used a colloid solution to optimize the patient's stroke volume and cardiac output [53]. Most of these studies demonstrated a benefit in favor of the GDFT group versus the control group, which should encourage our academic community to continue examining the potential benefits of colloid use moving forward. 


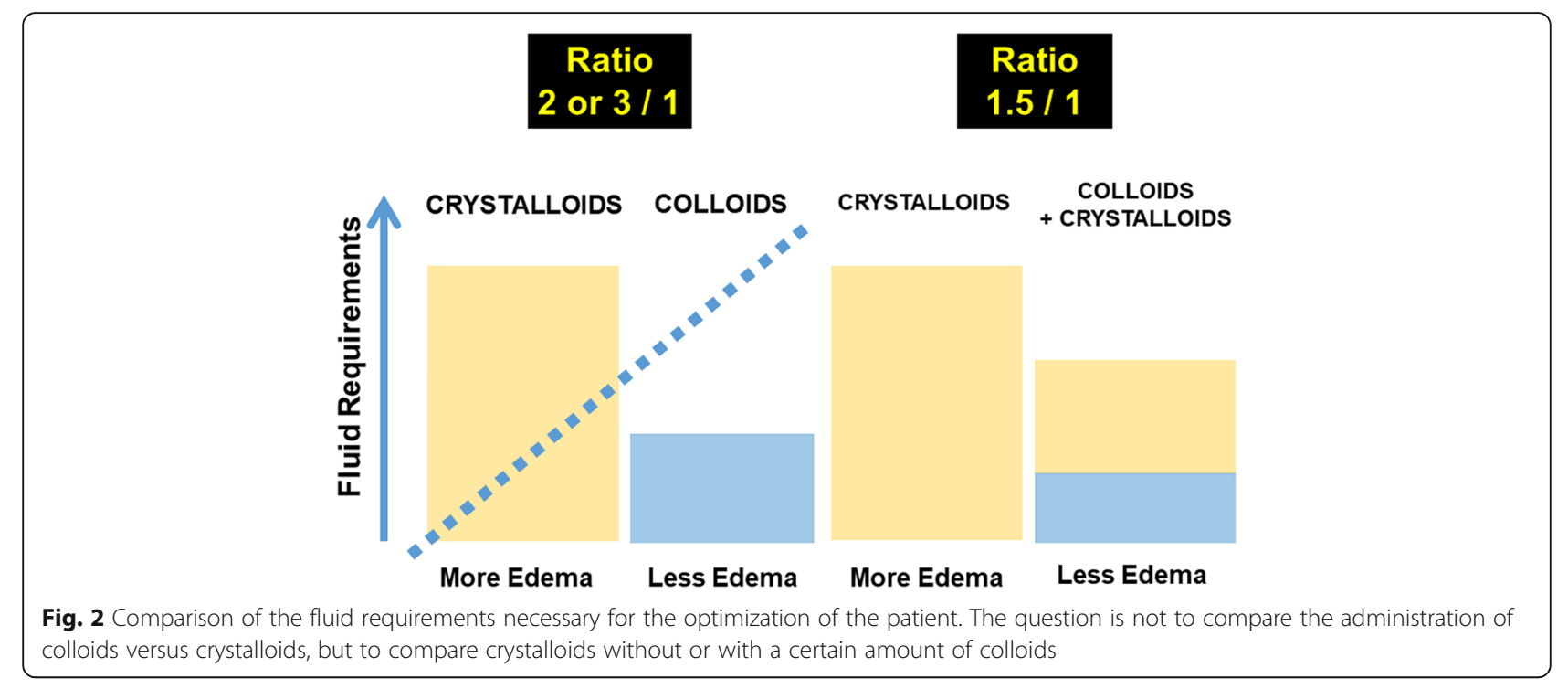

Question 4: is there a place for hydroxyethyl starch solutions?

YES.

Albumin is the most frequently used colloid solution and is considered to be the colloid solution of choice. The main limitations to its use are cost and availability, which have led to the development of synthetic colloid solutions as alternatives. Among synthetic colloid, starches are by far the most studied solutions.

HES solutions are plant-based (corn or potato) colloid solutions derived from the enzymatic hydrolysis of starch. Their properties are defined by molecular weight, degree of substitution, C2/C6 ratio and concentration. They are available as either $0.9 \%$ saline or balanced crystalloid solutions. The most recent (third) generation of HES solutions has a lower molecular weight, which maintains oncotic effects while simultaneously decreasing adverse events (i.e., hemostatic alterations, renal failure, and pruritus). The maximum daily recommended dose is $30 \mathrm{ml} / \mathrm{kg}$.

There is considerable controversy regarding the benefits and risks associated with the use of HES solutions. This controversy has stemmed from large multicenter studies in critically ill patients, and more specifically septic patients, which have reported adverse effects of HES solutions on mortality and/or renal function [68-70]. These studies have prompted the European Medicine Agency to restrict its use in the perioperative context. Several meta-analyses showed no association between HES administration and worse outcome in surgical patients $[71,72]$, so these concerns likely do not apply to short term intraoperative fluid expansion. Additionally, most studies that have demonstrated a benefit of GDFT over standard of care in high-risk surgical patients have used HES solutions to optimize stroke volume or cardiac output [53].

One small single-center, single-blinded randomized trial compared 5\% albumin solution to 6\% HES 130/0.4 solution used as part of a GDFT protocol in patients undergoing elective cystectomy [73]. There was no significant difference between the two groups with respect to the primary outcome, i.e., kidney function and kidney injury assessed up to postoperative day 90. Of note, the incidence of pruritus, evaluated by a questionnaire, was significantly higher in the albumin group.

Four double-blinded randomized studies have assessed the impact on patient outcome of HES 130/0.4 solution versus a crystalloid solution while standardizing the volume and timing of administration using a GDFT protocol $[56,57,74,75]$. Yates et al. reported no benefit of HES solution over Ringer's lactate (Hartmann) solution in terms of postoperative complications in 202 patients undergoing colorectal surgery [56]. However, in this monocenter study, $38 \%$ of patients in the crystalloid group received a rescue colloid solution (a gelatin) compared to $12 \%$ in the HES group. Interpretation of the results is thus challenging as this study actually compared two groups that received a combination of crystalloid and colloid solutions in different proportions. We observed that a HES-based GDFT was associated with a lower incidence of postoperative complications than a balanced crystalloid GDFT in 160 patients undergoing major abdominal surgery [57]. In a multicenter study $(N=1057)$, Kabon et al. reported that Doppler-guided intraoperative HES administration did not reduce a composite outcome of serious postoperative cardiac, pulmonary, infectious, gastrointestinal, renal and coagulation complications compared to lactated Ringer's 
solution in patients undergoing moderate-to-high risk abdominal surgery [74]. In another multicenter study of 775 patients at increased risk of postoperative kidney injury after major abdominal surgery, Futier et al. reported that HES solution used according to a stroke volumeguided hemodynamic therapy algorithm did not reduce a composite outcome of death or major postoperative complications compared to isotonic saline [75]. However, more patients in the HES group developed mild acute kidney injury $(P=.03)$ in the immediate postoperative period. In contrast, we did not observe any deleterious effect of HES solution on long-term (1 year) kidney function compared to a balanced crystalloid solution in our study population [76].

Not surprisingly, these four studies confirm what physiology tells us: to achieve a predefined hemodynamic target, a smaller volume of colloid solution, namely HES $130 / 0.4$, is required, compared to crystalloid solution, resulting in a less positive intraoperative fluid balance. Of note, several studies have reported an association between positive perioperative fluid balance and worse outcome [77-80]. However, among the four studies cited above, our study reported a reduced incidence of postoperative complications with the use of HES solution, associated with a lower intraoperative fluid balance [57]. Interestingly, the major difference between our study and the three others is the protocol used to guide fluid administration. While the three other studies $[68,69,71]$ used a pragmatic approach in which fluid boluses $(250 \mathrm{ml}$ fluid challenges) were administered manually by the clinician in charge of the patient in order to maximize stroke volume, we used a closed-loop delivery system in which small boluses (100 ml mini-fluid challenges) were administered automatically by a computer-controlled infusion pump with dedicated software that optimized stroke volume [70]. This system allowed strict standardization of fluid administration, increasing compliance with the protocol and improving the accuracy of implementation. The pragmatic approach used in the other studies, which reflects routine clinical practice, is inherently associated with lower protocol adherence and a high potential risk of protocol violations. When comparing our study to the study by Futier et al., the different strategies resulted in more "liberal" fluid administration in the Futier et al. study and a more "restrictive" approach in ours. However, the amount of HES solution infused in the colloid groups of the two studies was approximately the same $( \pm 1000 \mathrm{ml})$, whereas the total volume of crystalloid solution was much higher in the study by Futier et al. Consequently, cumulative net fluid balance on day one was also much more positive in this latter study (Fig. 3), which might explain the difference in the results reported in these two studies. In accordance with this hypothesis, fluid volume rather than fluid type may be responsible for the divergent results seen across the four studies. Importantly, the study of Joosten et al. [57] included the smaller number of patients compared to the three other ones [56, 74, 75]; their results need to be therefore confirmed. Two large randomized controlled trials (TETHYS trial [N=350] in trauma patients and PHOENICS trial $[N=2280]$ in elective abdominal surgical patients) are on the way. They should clearly help to precise the benefit to risk ratio associated with the use of HES in the two specific contexts. In the final debate, the price should be taken into account as HES solutions are much more expensive than crystalloid solutions, but significantly cheaper than albumin solutions in most European countries.

Fluid balance at POD1 $(\mathrm{mL})$

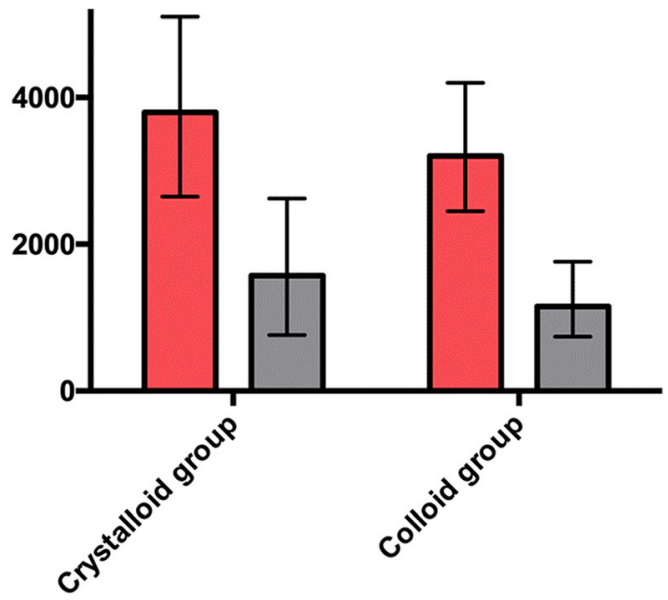

$\square$ Futier et al.

$\square$ Joosten etal.

Fig. 3 Comparison of fluid balance at postoperative day 1 (POD1) between the study of Futier et al vs Joosten et al 


\section{Conclusion}

In the perioperative setting, not only the type of fluid but also the volume administered can impact a patient's outcome following major surgery. Fluid volume should be guided by predefined physiologic targets, using an individualized hemodynamic algorithm. Clinician compliance with such protocols can be improved by using automated closed-loop systems that enable automation of some of the simple but restrictive therapeutic tasks. It is of prime importance that intravenous fluids be administered with the same care as any other drug, with strict indications and contraindications and precautions with regard to potential adverse effects. Finally, perioperative colloid solutions, and in particular HES solutions, may have a place in optimizing a patient's hemodynamic status while limiting the total volume of fluid administered. Large multicenter studies that assess the impact of crystalloids vs colloids and that apply a strict approach that ensures high protocol compliance, for example with a closed-loop system, are needed.

\section{Abbreviations}

GDFT: Goal directed fluid therapy; HES: Hydroxyethyl starch

\section{Acknowledgements}

NA

\section{Authors' contributions}

A.J.: Manuscript draft and approval of manuscript. S.C.: Manuscript draft and approval of manuscript. B.A.: Manuscript draft and approval of manuscript. A.D.: Manuscript draft and approval of manuscript. M.C.: Manuscript draft and approval of manuscript. J.D.: Manuscript draft and approval of manuscript. B.S: Manuscript draft and approval of manuscript. JL.V: Manuscript draft and approval of manuscript. PVdL: Manuscript draft and approval of manuscript. All authors have read and approved the final version of this manuscript.

\section{Funding}

This study was funded solely by departmental resources.

\section{Availability of data and materials}

NA

\section{Ethics approval and consent to participate}

NA

\section{Consent for publication}

Not applicable (review article).

\section{Competing interests}

AJ is consultants for Edwards Lifesciences (Irvine, CA, USA), for Fresenius Kabi (Bad Homburg, Germany) for Aguettant Laboratoire (Lyon, France) and is Associate Editor for the journal BMC Anesthesiology.

BS has received honoraria for consulting, honoraria for giving lectures, and refunds of travel expenses from Edwards Lifesciences Inc. (Irvine, CA, USA). BS has received honoraria for consulting, institutional restricted research grants, honoraria for giving lectures, and refunds of travel expenses from Pulsion Medical Systems SE (Feldkirchen, Germany). BS has received institutional restricted research grants, honoraria for giving lectures, and refunds of travel expenses from CNSystems Medizintechnik GmbH (Graz, Austria). BS has received institutional restricted research grants from Retia Medical LLC. (Valhalla, NY, USA). BS has received honoraria for giving lectures from Philips Medizin Systeme Böblingen GmbH (Böblingen, Germany). BS has received honoraria for consulting, institutional restricted research grants, and refunds of travel expenses from Tensys Medical Inc. (San Diego, CA, USA). S.C is Associate Editor for the journal BMC Anesthesiology.
JLV is Editor-in-Chief of Critical Care. He has no other conflicts related to this article.

P.VdL has received, within the past 5 years, fees for lectures and consultancies from Fresenius Kabi ((Bad Homburg, Germany) and Aguettant Laboratoire (Lyon, France) and Nordic Pharma, Belgium.

The other authors have no conflicts of interest to declare.

\section{Author details}

${ }^{1}$ Department of Anesthesiology, Erasme Hospital, Université Libre de Bruxelles, Brussels, Belgium. ${ }^{2}$ Department of Anesthesiology and Intensive Care, Hôpitaux Universitaires Paris-Sud, Université Paris-Sud, Université Paris-Saclay, Hôpital De Bicêtre, Assistance Publique Hôpitaux de Paris (AP-HP), Le Kremlin-Bicêtre, France. ${ }^{3}$ Department of Anesthesiology \& Perioperative Medicine, Bicêtre Hospital, 78, Rue du Général Leclerc, 94270 Le Kremlin-Bicêtre, France. ${ }^{4}$ Department of Anesthesiology \& Perioperative Care, University of California San Diego, San Diego, USA. ${ }^{5}$ Department of Anesthesiology \& Intensive Care, Marie Lannelongue Hospital, Paris, France. ${ }^{6}$ Department of Anesthesiology \& Perioperative Medicine, University of California Los Angeles, Los Angeles, USA. 'Department of Anesthesiology, Center of Anesthesiology and Intensive Care Medicine, University Medical Center Hamburg-Eppendorf, Hamburg, Germany. ${ }^{8}$ Outcomes Research Consortium, Cleveland, $\mathrm{OH}$, USA. ${ }^{9}$ Department of Intensive Care, Erasme Hospital, Université Libre de Bruxelles, Brussels, Belgium. ${ }^{10}$ Department of Anesthesiology, Brugmann Hospital, Université Libre de Bruxelles, Brussels, Belgium.

Received: 14 May 2020 Accepted: 12 August 2020

Published online: 20 August 2020

\section{References}

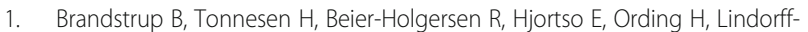
Larsen K, Rasmussen MS, Lanng C, Wallin L, Iversen LH, et al. Effects of intravenous fluid restriction on postoperative complications: comparison of two perioperative fluid regimens: a randomized assessor-blinded multicenter trial. Ann Surg. 2003;238(5):641-8.

2. Nisanevich V, Felsenstein I, Almogy G, Weissman C, Einav S, Matot I. Effect of intraoperative fluid management on outcome after intraabdominal surgery. Anesthesiology. 2005;103(1):25-32.

3. Shin CH, Long DR, McLean D, Grabitz SD, Ladha K, Timm FP, Thevathasan T, Pieretti A, Ferrone C, Hoeft A, et al. Effects of intraoperative fluid management on postoperative outcomes: a hospital registry study. Ann Surg. 2018;267(6):1084-92.

4. Thacker JK, Mountford WK, Ernst FR, Krukas MR, Mythen MM. Perioperative fluid utilization variability and association with outcomes: considerations for enhanced recovery efforts in sample US surgical populations. Ann Surg. 2016;263(3):502-10.

5. Myles PS, Bellomo R. Restrictive or Liberal fluid therapy for major abdominal surgery. N Engl J Med. 2018;379(13):1283.

6. Holte K, Sharrock NE, Kehlet H. Pathophysiology and clinical implications of perioperative fluid excess. Br J Anaesth. 2002;89(4):622-32.

7. Vallet B, Blanloeil Y, Cholley B, Orliaguet G, Pierre S, Tavernier B. Guidelines for perioperative haemodynamic optimization. Ann Fr Anesth Reanim. 2013; 32(10):e151-8

8. Michard F, Giglio MT, Brienza N. Perioperative goal-directed therapy with uncalibrated pulse contour methods: impact on fluid management and postoperative outcome. Br J Anaesth. 2017;119(1):22-30.

9. Cannesson M, Ramsingh D, Rinehart J, Demirjian A, Vu T, Vakharia S, Imagawa D, Yu Z, Greenfield S, Kain Z. Perioperative goal-directed therapy and postoperative outcomes in patients undergoing high-risk abdominal surgery: a historical-prospective, comparative effectiveness study. Crit Care (London, England). 2015;19:261.

10. NICE draft guidance on cardiac output monitoring device published for consultation. http://www.nice.org.uk/newsroom/pressreleases/ DraftGuidanceOnCardiacOutputMonitoringDevice.jsp.

11. Chong MA, Wang Y, Berbenetz NM, McConachie I. Does goal-directed haemodynamic and fluid therapy improve peri-operative outcomes?: a systematic review and meta-analysis. Eur J Anaesthesiol. 2018;35(7):469-83.

12. Jin J, Min S, Liu D, Liu L, Lv B. Clinical and economic impact of goal-directed fluid therapy during elective gastrointestinal surgery. Perioper Med (London, England). 2018;7:22. 
13. Michard F, Mountford WK, Krukas MR, Ernst FR, Fogel SL. Potential return on investment for implementation of perioperative goal-directed fluid therapy in major surgery: a nationwide database study. Perioper Med (London, England). 2015;4:11.

14. Myburgh JA, Mythen MG. Resuscitation fluids. N Engl J Med. 2013;369(13): 1243-51.

15. Hoste EA, Maitland K, Brudney CS, Mehta R, Vincent JL, Yates D, Kellum JA, Mythen MG, Shaw AD. Four phases of intravenous fluid therapy: a conceptual model. Br J Anaesth. 2014;113(5):740-7.

16. Malbrain M, Langer T, Annane D, Gattinoni L, Elbers P, Hahn RG, De Laet I, Minini A, Wong A, Ince C, et al. Intravenous fluid therapy in the perioperative and critical care setting: executive summary of the international fluid academy (IFA). Ann Intensive Care. 2020;10(1):64.

17. Deng QW, Tan WC, Zhao BC, Wen SH, Shen JT, Xu M. Is goal-directed fluid therapy based on dynamic variables alone sufficient to improve clinical outcomes among patients undergoing surgery? Meta Anal. 2018; 22(1):298.

18. Brienza N, Giglio MT, Marucci M, Fiore T. Does perioperative hemodynamic optimization protect renal function in surgical patients? A meta-analytic study. Crit Care Med. 2009;37(6):2079-90.

19. Giglio M, Manca F, Dalfino L, Brienza N. Perioperative hemodynamic goaldirected therapy and mortality: a systematic review and meta-analysis with meta-regression. Minerva Anestesiol. 2016;82(11):1199-213.

20. Giglio M, Dalfino L, Puntillo F, Brienza N. Hemodynamic goal-directed therapy and postoperative kidney injury: an updated meta-analysis with trial sequential analysis. Crit Care (London, England). 2019:23(1):232.

21. Pestana D, Espinosa E, Eden A, Najera D, Collar L, Aldecoa C, Higuera E, Escribano S, Bystritski D, Pascual J, et al. Perioperative goal-directed hemodynamic optimization using noninvasive cardiac output monitoring in major abdominal surgery: a prospective, randomized, multicenter, pragmatic trial: POEMAS study (PeriOperative goal-directed thErapy in major abdominal surgery). Anesth Analg. 2014;119(3):579-87.

22. Davies SJ, Yates DR, Wilson RJT, Murphy Z, Gibson A, Allgar V, Collyer T. A randomised trial of non-invasive cardiac output monitoring to guide haemodynamic optimisation in high risk patients undergoing urgent surgical repair of proximal femoral fractures (ClearNOF trial NCT02382185). Perioper Med (London, England). 2019:8:8.

23. Fischer $M O$, Fiant $A L$, Debroczi $S$, Boutros M, Pasqualini $L$, Demonchy $M$, Flais F, Alves A, Gerard JL, Buleon C, et al. Perioperative non-invasive haemodynamic optimisation using photoplethysmography: a randomised controlled trial and meta-analysis. Anaesth Crit Care Pain Med. 2020;39(3): 421-428.

24. Fischer MO, Lemoine S, Tavernier B, Bouchakour CE, Colas V, Houard M, Greub W, Daccache G, Hulet C, Compere V, et al. Individualized fluid management using the Pleth variability index: a randomized clinical trial. Anesthesiology. 2020;133(1):31-40

25. Pearse RM, Harrison DA, MacDonald N, Gillies MA, Blunt M, Ackland G, Grocott MP, Ahern A, Griggs K, Scott R, et al. Effect of a perioperative, cardiac output-guided hemodynamic therapy algorithm on outcomes following major gastrointestinal surgery: a randomized clinical trial and systematic review. JAMA. 2014;311(21):2181-90.

26. Challand C, Struthers R, Sneyd JR, Erasmus PD, Mellor N, Hosie KB, Minto G. Randomized controlled trial of intraoperative goal-directed fluid therapy in aerobically fit and unfit patients having major colorectal surgery. $\mathrm{Br} \mathrm{J}$ Anaesth. 2012;108(1):53-62.

27. Joosten A, Raj Lawrence S, Colesnicenco A, Coeckelenbergh S, Vincent JL, Van der Linden P, Cannesson M, Rinehart J. Personalized versus Protocolized fluid management using noninvasive hemodynamic monitoring (Clearsight system) in patients undergoing moderate-risk abdominal surgery. Anesth Analg. 2019;129(1):e8-e12.

28. Stens J, Hering JP, van der Hoeven CWP, Boom A, Traast HS, Garmers LE, Loer SA, Boer C. The added value of cardiac index and pulse pressure variation monitoring to mean arterial pressure-guided volume therapy in moderate-risk abdominal surgery (COGUIDE): a pragmatic multicentre randomised controlled trial. Anaesthesia. 2017;72(9):1078-87.

29. Joosten A, Rinehart J, Cannesson M. Perioperative goal directed therapy: evidence and compliance are two sides of the same coin. Rev Esp Anestesiol Reanim. 2015;62(4):181-3.

30. Kozek-Langenecker SA, Afshari A, Albaladejo P, Santullano CA, De Robertis E, Filipescu DC, Fries D, Görlinger K, Haas T, Imberger G, et al. Management of severe perioperative bleeding: guidelines from the European Society of Anaesthesiology. Eur J Anaesthesiol. 2013;30(6):270-382.

31. Spahn DR, Bouillon B, Cerny V, Duranteau J, Filipescu D, Hunt BJ, Komadina $R$, Maegele M, Nardi G, Riddez L, et al. The European quideline on management of major bleeding and coagulopathy following trauma: fifth edition. Crit Care (London, England). 2019;23(1):98.

32. Godier A, Bacus M, Kipnis E, Tavernier B, Guidat A, Rauch A, Drumez E, Susen S, Garrigue-Huet D. Compliance with evidence-based clinical management guidelines in bleeding trauma patients. Br J Anaesth. 2016; 117(5):592-600

33. Joosten A, Desebbe O, Suehiro K, Murphy LS, Essiet M, Alexander B, Fischer MO, Barvais L, Van Obbergh L, Maucort-Boulch D, et al. Accuracy and precision of non-invasive cardiac output monitoring devices in perioperative medicine: a systematic review and meta-analysisdagger. $\mathrm{Br} J$ Anaesth. 2017;118(3):298-310.

34. Suehiro KJ, Alexander A, Cannesson B. M: Guiding goal directed therapy. Curr Anesthesiolol Rep. 2014:4:360-75.

35. Habicher M, Balzer F, Mezger V, Niclas J, Muller M, Perka C, Kramer M, Sander M. Implementation of goal-directed fluid therapy during hip revision arthroplasty: a matched cohort study. Perioper Med (London, England). 2016:5:31

36. Lipton JA, Barendse RJ, Schinkel AF, Akkerhuis KM, Simoons ML, Sijbrands EJ. Impact of an alerting clinical decision support system for glucose control on protocol compliance and glycemic control in the intensive cardiac care unit. Diabetes Technol Ther. 2011;13(3):343-9.

37. Spanjersberg WR, Bergs EA, Mushkudiani N, Klimek M, Schipper IB. Protocol compliance and time management in blunt trauma resuscitation. Emerg Med J. 2009;26(1):23-7.

38. Simpson JC, Moonesinghe SR, Grocott MP, Kuper M, McMeeking A, Oliver CM, Galsworthy MJ, Mythen MG. Enhanced recovery from surgery in the UK: an audit of the enhanced recovery partnership programme 2009-2012. Br J Anaesth. 2015;115(4):560-8.

39. Menger J, Fischer A, Mouhieddine M, Seidel M, Edlinger-Stanger $M$, Bevilacqua M, Hiesmayr M, Dworschak M. Evaluation of an active decision support system for hemodynamic optimization during elective major vascular surgery. Minerva Anestesiol. 2019;85(3):288-97.

40. Joosten A, Alexander B, Duranteau J. Clinical decision support system clears the way for perioperative goal directed therapy protocol adherence improvement. Minerva Anestesiol. 2019;85(6):691-2.

41. Joosten A, Alexander B, Delaporte A, Lilot M, Rinehart J, Cannesson M. Perioperative goal directed therapy using automated closed-loop fluid management: the future? Anaesthesiol Intensive Ther. 2015:47(5):517-23.

42. Joosten A, Jame V, Alexander B, Chazot T, Liu N, Cannesson M, Rinehart J, Barvais L. Feasibility of fully automated hypnosis, analgesia, and fluid management using 2 independent closed-loop systems during major vascular surgery: a pilot study. Anesth Analg. 2019;128(6):e88-92.

43. Joosten A, Huynh T, Suehiro K, Canales C, Cannesson M, Rinehart J. Goaldirected fluid therapy with closed-loop assistance during moderate risk surgery using noninvasive cardiac output monitoring: a pilot study. $\mathrm{Br}$ J Anaesth. 2015;114(6):886-92.

44. Rinehart J, Lilot M, Lee C, Joosten A, Huynh T, Canales C, Imagawa D, Demirjian A, Cannesson M. Closed-loop assisted versus manual goaldirected fluid therapy during high-risk abdominal surgery: a casecontrol study with propensity matching. Crit Care (London, England). 2015;19:94.

45. Joosten A, Coeckelenbergh S, Delaporte A, Ickx B, Closset J, Roumeguere T, Barvais L, Van Obbergh L, Cannesson M, Rinehart J, et al. Implementation of closed-loop-assisted intra-operative goal-directed fluid therapy during major abdominal surgery: a case-control study with propensity matching. Eur J Anaesthesiol. 2018;35(9):650-8.

46. Joosten A, Hafiane R, Pustetto M, Van Obbergh L, Quackels T, Buggenhout A, Vincent JL, Ickx B, Rinehart J. Practical impact of a decision support for goal-directed fluid therapy on protocol adherence: a clinical implementation study in patients undergoing major abdominal surgery. J Clin Monit Comput. 2019;33(1):15-24.

47. Joosten A, Alexander B, Duranteau J, Taccone FS, Creteur J, Vincent JL, Cannesson M, Rinehart J. Feasibility of closed-loop titration of norepinephrine infusion in patients undergoing moderate- and high-risk surgery. Br J Anaesth. 2019;123(4):430-438.

48. Joosten A, Delaporte A, Alexander B, Su F, Creteur J, Vincent JL, Cannesson $M$, Rinehart J. Automated titration of vasopressor infusion using a closed- 
loop controller: in vivo feasibility study using a swine model. Anesthesiology. 2019;130(3):394-403.

49. Rinehart J, Cannesson M, Weeraman S, Barvais L, Obbergh LV, Joosten A. Closed-loop control of vasopressor Administration in Patients Undergoing Cardiac Revascularization Surgery. J Cardiothorac Vasc Anesth. 2020;510530770(20)30287-1. https://doi.org/10.1053/j.jvca.2020.03.038. Online ahead of print.

50. Joosten A, Coeckelenbergh S, Alexander B, Cannesson M, Rinehart J. Feasibility of computer-assisted vasopressor infusion using continuous noninvasive blood pressure monitoring in high-risk patients undergoing renal transplant surgery. Anaesth Crit Care Pain Med. 2020;S2352-5568(20)30060-6. https://doi.org/10.1016/j.accpm.2019.12.011.

51. Rinehart J, Joosten A, Ma M, Calderon MD, Cannesson M. Closed-loop vasopressor control: in-silico study of robustness against pharmacodynamic variability. J Clin Monit Comput. 2019:33(5):795-802.

52. Rinehart J, Ma M, Calderon MD, Cannesson M. Feasibility of automated titration of vasopressor infusions using a novel closed-loop controller. J Clin Monit Comput. 2018;32(1):5-11.

53. Messina A, Pelaia C, Bruni A, Garofalo E, Bonicolini E, Longhini F, Dellara E, Saderi L, Romagnoli S, Sotgiu G, et al. Fluid challenge during anesthesia: a systematic review and meta-analysis. Anesth Analg. 2018; 127(6):1353-64.

54. Orbegozo Cortes D, Gamarano Barros T, Njimi H, Vincent JL. Crystalloids versus colloids: exploring differences in fluid requirements by systematic review and meta-regression. Anesth Analg. 2015;120(2):389-402.

55. Feldheiser A, Pavlova V, Bonomo T, Jones A, Fotopoulou C, Sehouli J, Wernecke KD, Spies C. Balanced crystalloid compared with balanced colloid solution using a goal-directed haemodynamic algorithm. Br J Anaesth. 2013; 110(2):231-40.

56. Yates DR, Davies SJ, Milner HE, Wilson RJ. Crystalloid or colloid for goaldirected fluid therapy in colorectal surgery. Br J Anaesth. 2014;112(2):281-9.

57. Joosten A, Delaporte A, Ickx B, Touihri K, Stany I, Barvais L, Van Obbergh L, Loi P, Rinehart J, Cannesson M, et al. Crystalloid versus colloid for intraoperative goal-directed fluid therapy using a closed-loop system: a randomized, double-blinded, controlled trial in major abdominal surgery. Anesthesiology. 2018;128(1):55-66.

58. Jacob M, Chappell D, Hofmann-Kiefer K, Helfen T, Schuelke A, Jacob B, Burges $\mathrm{A}$, Conzen $\mathrm{P}$, Rehm M. The intravascular volume effect of Ringer's lactate is below 20\%: a prospective study in humans. Crit Care (London, England). 2012;16(3):R86.

59. Hiltebrand LB, Kimberger O, Arnberger M, Brandt S, Kurz A, Sigurdsson GH. Crystalloids versus colloids for goal-directed fluid therapy in major surgery. Crit Care (London, England). 2009;13(2):R40.

60. Marjanovic G, Villain C, Juettner E, zur Hausen A, Hoeppner J, Hopt UT, Drognitz O, Obermaier R. Impact of different crystalloid volume regimes on intestinal anastomotic stability. Ann Surg. 2009;249(2):181-5.

61. Reid F, Lobo DN, Williams RN, Rowlands BJ, Allison SP. (Ab) normal saline and physiological Hartmann's solution: a randomized double-blind crossover study. Clin Sci (London, England: 1979). 2003;104(1):17-24.

62. Jacob M, Chappell D, Rehm M. Clinical update: perioperative fluid management. Lancet (London, England). 2007;369(9578):1984-6.

63. Rehm M, Orth V, Kreimeier U, Thiel M, Haller M, Brechtelsbauer H, Finsterer $U$. Changes in intravascular volume during acute normovolemic hemodilution and intraoperative retransfusion in patients with radical hysterectomy. Anesthesiology. 2000;92(3):657-64.

64. Jacob M, Rehm M, Orth V, Lötsch M, Brechtelsbauer H, Weninger E, Finsterer U. Exact measurement of the volume effect of $6 \%$ hydoxyethyl starch 130/0. 4 (Voluven) during acute preoperative normovolemic hemodilution. Anaesthesist. 2003:52(10):896-904.

65. Rehm M, Haller M, Orth V, Kreimeier U, Jacob M, Dressel H, Mayer S, Brechtelsbauer $\mathrm{H}$, Finsterer $\mathrm{U}$. Changes in blood volume and hematocrit during acute preoperative volume loading with $5 \%$ albumin or $6 \%$ hetastarch solutions in patients before radical hysterectomy. Anesthesiology. 2001:95(4):849-56.

66. Chappell D, Jacob M, Hofmann-Kiefer K, Conzen P, Rehm M. A rational approach to perioperative fluid management. Anesthesiology. 2008;109(4): 723-40.

67. Annane D, Siami S, Jaber S, Martin C, Elatrous S, Declere AD, Preiser JC, Outin $H$, Troche G, Charpentier C, et al. Effects of fluid resuscitation with colloids vs crystalloids on mortality in critically ill patients presenting with hypovolemic shock: the CRISTAL randomized trial. JAMA. 2013;310(17):1809-17.
68. Myburgh JA, Finfer S, Billot L. Hydroxyethyl starch or saline in intensive care. N Engl J Med. 2013;368(8):775.

69. Perner A, Haase N, Guttormsen AB, Tenhunen J, Klemenzson G, Aneman A, Madsen KR, Moller MH, Elkjaer JM, Poulsen LM, et al. Hydroxyethyl starch 130/0.42 versus Ringer's acetate in severe sepsis. N Engl J Med. 2012;367(2): 124-34.

70. Brunkhorst FM, Engel C, Bloos F, Meier-Hellmann A, Ragaller M, Weiler N, Moerer $\mathrm{O}$, Gruendling M, Oppert M, Grond S, et al. Intensive insulin therapy and pentastarch resuscitation in severe sepsis. N Engl J Med. 2008;358(2): 125-39.

71. Jacob M, Fellahi IL, Chappell D, Kurz A. The impact of hydroxyethyl starches in cardiac surgery: a meta-analysis. Crit Care (London, England). 2014;18(6):656.

72. Van Der Linden P, James M, Mythen M, Weiskopf RB. Safety of modern starches used during surgery. Anesth Analg. 2013;116(1):35-48.

73. Kammerer T, Brettner F, Hilferink S, Hulde N, Klug F, Pagel J, Karl A, Crispin A, Hofmann-Kiefer K, Conzen P, et al. No differences in renal function between balanced 6\% Hydroxyethyl starch (130/0.4) and 5\% albumin for volume replacement therapy in patients undergoing cystectomy: a randomized controlled trial. Anesthesiology. 2018;128(1):67-78.

74. Kabon B, Sessler DI, Kurz A. Effect of intraoperative goal-directed balanced crystalloid versus colloid administration on major postoperative morbidity: a randomized trial. Anesthesiology. 2019;130(5):728-44.

75. Futier E, Garot M, Godet T, Biais M, Verzilli D, Ouattara A, Huet O, Lescot T, Lebuffe G, Dewitte A, et al. Effect of Hydroxyethyl starch vs saline for volume replacement therapy on death or postoperative complications among high-risk patients undergoing major abdominal surgery: the FLASH randomized clinical trial. JAMA. 2020;323(3):225-36.

76. Joosten A, Delaporte A, Mortier J, ICkx B, Van Obbergh L, Vincent JL, Cannesson M, Rinehart J, Van der Linden P. Long-term impact of crystalloid versus colloid solutions on renal function and disability-free survival after major abdominal surgery. Anesthesiology. 2019;130(2):227-36.

77. Silva JM Jr, de Oliveira AM, Nogueira FA, Vianna PM, Pereira Filho MC, Dias LF, Maia VP, Neucamp Cde S, Amendola CP, Carmona MJ, et al. The effect of excess fluid balance on the mortality rate of surgical patients: a multicenter prospective study. Crit care (London, England). 2013;17(6):R288.

78. Smith BB, Mauermann WJ, Yalamuri SM, Frank RD, Gurrieri C, Arghami A, Smith MM. Intraoperative Fluid Balance and Perioperative Outcomes After Aortic Valve Surgery. Ann Thorac Surg. 2020;50003-4975(20)30351-9. https:// doi.org/10.1016/j.athoracsur.2020.01.081

79. Zhang S, Ma J, An R, Liu L, Li J, Fang Z, Wang Q, Ma Q, Shen X. Effect of cumulative fluid balance on acute kidney injury and patient outcomes after orthotopic liver transplantation: A retrospective cohort study. Nephrology (Carlton, Vic). 2020;25(9):700-7.

80. Codes L, de Souza YG, D'Oliveira RAC, Bastos JLA, Bittencourt PL. Cumulative positive fluid balance is a risk factor for acute kidney injury and requirement for renal replacement therapy after liver transplantation. World I Transplant. 2018;8(2):44-51.

\section{Publisher's Note}

Springer Nature remains neutral with regard to jurisdictional claims in published maps and institutional affiliations.

Ready to submit your research? Choose BMC and benefit from:

- fast, convenient online submission

- thorough peer review by experienced researchers in your field

- rapid publication on acceptance

- support for research data, including large and complex data types

- gold Open Access which fosters wider collaboration and increased citations

- maximum visibility for your research: over $100 \mathrm{M}$ website views per year

At BMC, research is always in progress.

Learn more biomedcentral.com/submissions 